\title{
Impact of clinical decision support on empiric antibiotic prescribing for children with community acquired pneumonia
}

\author{
Abstract \\ Aim: Assess the impact of a computerised clinical decision support system (CDSS) on antibiotic use \\ in hospitalised children with a presumptive diagnosis of uncomplicated community acquired \\ pneumonia (CAP).
}

Methods: Codes associated with lower respiratory tract infection were used to identify cases of presumed uncomplicated CAP requiring admission to a tertiary paediatric hospital. Random sampling of the periods between 1 October 2010 to 30 September 2012 (pre-CDSS) and 1 October 2012 to 30 September 2014 (post-CDSS) determined the sequence of case assessment by two independent investigators. Initial antibiotic therapy, associated CDSS approvals and documented signs of clinical deterioration prior to antibiotic decision-making were recorded.

Results: Statistically significant differences among cases pre- and post-CDSS implementation were minimal. High fever was observed in 57.5\% (77/134) cases pre-CDSS, and 45.8\% (49/107) cases post-CDSS ( $\mathrm{p}=0.07$ ). Supplemental oxygen was used in 30.6\% pre-CDSS, and 54.2\% post-CDSS cases $(\mathrm{p}<0.001)$. Narrow-spectrum penicillins were prescribed most often with no statistically significant change post-CDSS implementation ( $81.3 \%$ pre-CDSS, $77.6 \%$ post-CDSS, $\mathrm{p}=0.47$ ). Macrolides were used consistently throughout the study period (53.7\% pre-CDSS, $61.7 \%$ post-CDSS; $\mathrm{p}=0.21)$.

Conclusion: CDSS implementation did not reduce already low rates of broad-spectrum antibiotic use for uncomplicated CAP.

Keywords: Practice Guidelines as Topic; Practice Patterns, Physicians'; Community-Acquired Infections; Anti-infective Agents; Child

This is the author manuscript accepted for publication and has undergone full peer review but has not been through the copyediting, typesetting, pagination and proofreading process, which may lead to differences between this version and the Version of Record. Please cite this article as doi: $10.1111 /$ jpc.14191 


\section{What is already known on this topic}

- Community acquired pneumonia (CAP) is a common cause for hospitalisation in children.

- High rates of inappropriate broad-spectrum antibiotic use for uncomplicated CAP have made adherence to CAP guidelines a focus for antimicrobial stewardship (AMS).

- Clinical decision support and approval systems (CDSS) are frequently used to promote guideline adherence and facilitate AMS.

\section{What this paper adds}

- Over $80 \%$ of uncomplicated CAP cases in a tertiary paediatric hospital were treated with guideline concordant empiric antibiotics pre-CDSS.

- Restricted antibiotics were used infrequently post-CDSS. However, not one instance of restricted antibiotic use was associated with a documented CDSS approval.

- A standalone CDSS did not impact broad-spectrum antibiotic use for CAP (pre-CDSS 12.7\%, post-CDSS $13.1 \%, \mathrm{p}=0.927$ ) 


\section{Background}

Community acquired pneumonia (CAP) in infants and children is predominantly due to viral infection, with bacterial pneumonias most often caused by Streptococcus pneumoniae and less frequently "atypical” pathogens such as Mycoplasma pneumoniae. ${ }^{1}$ Guidelines typically recommend hospitalised children with uncomplicated CAP are treated with narrow-spectrum penicillins, either alone or in combination with a macrolide antibiotic where infection with an atypical pathogen is suspected. ${ }^{2}$ Broad-spectrum antibiotics such as third generation cephalosporins are generally reserved for when penicillin-resistant pathogens are suspected, such as in unimmunised children or children with severe pneumonia and empyema. ${ }^{2}$

Despite published evidence indicating that treatment with narrow-spectrum antibiotics does not increase the length of hospitalisation (LOS), morbidity or hospital costs ${ }^{3}$, broad-spectrum antibiotics continue to be over-prescribed, even after guidelines are implemented locally. ${ }^{4}$ Therefore, CAP is a common focus for antimicrobial stewardship (AMS) practice and research.

AMS involves the use of multiple strategies to optimise antimicrobial prescribing to achieve the best possible patient outcome and limit super-infection with opportunistic pathogens, toxicity, and the promotion of resistant organisms. ${ }^{5}$ As CAP contributes substantially to antimicrobial use in tertiary paediatric hospitals, targeting adherence to CAP guidelines is likely to significantly impact the overall appropriateness of hospital antimicrobial use. ${ }^{6}$ 
We assessed the impact of an AMS program with a computerised clinical decision support system (CDSS) on antibiotic use when treating children hospitalised with a presumptive diagnosis of uncomplicated CAP.

\section{Methods and Materials}

Setting

This study was conducted in a 170-bed university-affiliated tertiary paediatric hospital with specialist services in oncology, intensive care, solid organ transplant and cystic fibrosis in New South Wales, Australia.

Since October 2012 the hospital's AMS program has been supported by a CDSS (Guidance MS, Melbourne Health, Australia) to facilitate approval to use restricted antimicrobials. Prescribers are required to seek approval via the CDSS prior to initiating restricted antimicrobials. Automatic CDSS approval can be obtained for restricted antimicrobials when prescribed according to hospital guidelines. Therefore, for severe or complicated CAP automatic CDSS approvals are generated for: third generation cephalosporins and lincosamides for CAP requiring intensive care and patients with empyema or pneumatocele; glycopeptides (vancomycin) for CAP with signs of sepsis; and azithromycin if CAP is severe and an atypical pathogen is suspected. However, roxithromycin is recommended for less severe cases (Figure 1). Where the intended use for a restricted antimicrobial is not consistent with hospital guidelines a limited 24-hour approval is granted, with further approval subject to direct consultation with the AMS team.

From May to October 2012 the Infectious Diseases team and Chair of the hospital's drug committee led a range of activities to prepare staff for the introduction of the CDSS. Activities included notifications to heads of department and discussions between Infectious Diseases and representatives from hospital departments for consensus on the antimicrobial restriction categories, approval requirements, indications suitable for automatic approval as well as the specific dosage and frequency recommended within the CDSS. As part of AMS implementation in October 2012, junior and senior medical staff were formally introduced to the CDSS and trained on its use. Since then, AMS and CDSS orientation have been embedded within hospital orientation programs for junior medical staff at each new term rotation. Lanyard cards indicating the antimicrobial restriction categories and empiric 
antibiotic recommendations for common infections including CAP are available for all staff and given to all prescribers and pharmacists during hospital orientation.

Study design and data source

This retrospective clinical audit of medical records used The International Statistical Classification of Diseases and Related Health Problems Australian Modification 10 ${ }^{\text {th }}$ Revision (ICD-10-AM) codes associated with lower respiratory tract infections (Online Supplement 1) to identify potential cases of CAP in patients up to 18 years of age presenting between 1 October 2010 to 30 September 2012 (preCDSS) and 1 October 2012 to 30 September 2014 (post-CDSS). The hospital's health information unit extracted patient demographic and admission information for all potential cases, including the admission date, LOS and unplanned readmissions within 28 days. Patients directly transferred to the intensive care unit (ICU) and those admitted to hospital after being discharged within the previous 30 days were excluded.

Potential cases in each of the pre-CDSS and post-CDSS periods were numbered in chronological order. A random number generator was used to randomly sample potential cases in each period for independent assessment by two investigators. Both investigators reviewed medical records relating to each sampled admission. Cases were included where the emergency department (ED) physician or the admitting medical team physician clearly documented a clinical impression of pneumonia as the reason for admission with use of the terms "CAP", "pneumonia", "lower respiratory tract infection", "LRTI", "pneumonitis", "mycoplasma", "viral pneumonia", or evidence of a chest x-ray accompanied by a documented clinical impression of respiratory tract infection and prescription of at least one antibiotic.

We sought to limit cases to those for whom hospital guidelines recommend penicillin therapy, with or without a macrolide. Therefore, we excluded patients with documented chronic cardiac or respiratory disease (e.g. cystic fibrosis, chronic suppurative lung disease), immunodeficiency (cancer, solid organ transplant, or opportunistic infection), documented clinical impression of aspiration pneumonia, empyema or pleural effusion; patients assigned a 'high acuity' bed; or those who had not been immunised. 
Cases were included if there was consensus among the investigators regarding eligibility. The process continued until a sufficient number of eligible cases in each of the pre-CDSS and post-CDSS periods were identified.

Data collection

Investigators recorded the initial CAP diagnosis documented in the medical record and whether the initial antibiotic therapy prescribed on the medication chart included a penicillin, third generation cephalosporin, macrolide, lincosamide or glycopeptide. The specific macrolide antibiotic was also documented. Where a restricted antibiotic was prescribed post-CDSS the CDSS database was queried to confirm whether approval was obtained.

Observation charts were reviewed from the time of hospital presentation to the time of antibiotic selection. Where the time of selection could not be determined from the prescriber's note the antibiotic administration time documented on the medication chart was used as a substitute. Investigators recorded whether there were any documented observations indicating respiratory distress, tachypnoea, tachycardia, altered consciousness (Alert Verbal Pain Unresponsive Scale or Glasgow Coma Scale), fever (temperature greater than $38.5^{\circ} \mathrm{C}$ ) and if supplemental oxygen was required at any time prior to antibiotic selection. Unless stated, high acuity ranges were determined from the hospital's age-specific criteria which mandate urgent clinical review by a medical officer (Figure 2). ${ }^{7}$

\section{Sample size}

Assuming local prescribing was similar to published CAP evaluations we estimated the pre-CDSS rate of inappropriate third generation cephalosporin use in uncomplicated CAP to be $50 \%{ }^{8} \mathrm{We}$ determined that 170 cases in each of the pre- and post-CDSS periods would be required to demonstrate a $15 \%$ reduction (alpha 0.05 , power 0.8 ; $\mathrm{G}^{*}$ Power version 3.1.9.2). ${ }^{9}$

Data analysis

Statistical analysis was performed in SPSS ${ }^{\mathrm{TM}}$ version 24 (IBM, Armonk NY, USA). Chi-square tests were used to compare differences in characteristics and antibiotic prescribing pre-CDSS and postCDSS. LOS was measured in days and treated as a continuous variable. The median LOS before and 
after CDSS was compared using the Mann-Whitney U-test. All statistical tests were two-tailed with $p$ values of $<0.05$ considered statistically significant.

\section{Results}

ICD-10-AM codes identified 697 potential cases overall. Investigators assessed 584 cases and included 134 pre-CDSS and 107 post-CDSS cases; 113 records were not available for review. Cases were frequently excluded due to a significant past medical history, complication, or treatment for an alternate condition at admission (Figure 3).

All cases were at least 3 months old, with a similar proportion under 12 months of age at admission (10.5\% cases pre-CDSS, $8.4 \%$ cases post-CDSS). There were no significant differences in LOS or unplanned readmissions pre- and post-CDSS. Most cases didn't have a presumed pathogen documented by the prescriber at the time of antibiotic selection (Table 1).

From the time of admission to antibiotic selection, one or more urgent reviews were required for tachypnoea ( $13.4 \%$ cases pre-CDSS versus $16.8 \%$ cases post-CDSS; $\mathrm{p}=0.46)$, respiratory distress (3.0\% versus $3.7 \% ; p=0.75)$, and tachycardia $(13.4 \%$ versus $17.8 \% ; p=0.36)$. High fever was observed in $57.5 \%$ and $45.8 \%$ of cases pre- and post-CDSS respectively ( $\mathrm{p}=0.07$ ). Supplemental oxygen was administered more often post-CDSS $(30.6 \%$ cases pre-CDSS, $54.2 \%$ cases post-CDSS; $p<0.001$ ) (Table 1).

There were no statistically significant changes to antibiotic prescribing after CDSS implementation. Third generation cephalosporins were prescribed in only $12.7 \%$ of cases pre-CDSS and $13.1 \%$ of cases post-CDSS (Table 2). Of these, one case post-CDSS involved a possible penicillin allergy whereby the reaction, type and date of reaction were incompletely documented. Despite the initial choice to prescribe a broad-spectrum agent, narrow-spectrum penicillins were prescribed shortly thereafter. Penicillins were the initial antibiotic of choice prescribed in $81.3 \%$ and $77.6 \%$ of cases pre- and post-CDSS $(\mathrm{p}=0.47)$. Both macrolide prescribing and dual antibiotic therapy increased marginally post-CDSS, particularly where penicillins were used. Roxithromycin remained the macrolide of choice, used in $50.6 \%$ of cases pre-CDSS and $57.0 \%$ of cases post-CDSS implementation. Other antibiotics were used infrequently; neither clarithromycin nor glycopeptides 
were used for any episode of uncomplicated CAP. None of the 17 instances of restricted antibiotic use post-CDSS were associated with a CDSS approval.

\section{Discussion}

There are no validated CAP severity scores for children ${ }^{10}$ and prognostic indicators are limited. ${ }^{11}$ Therefore, we anticipated high rates of inappropriate prescribing and estimated approximately $50 \%$ of uncomplicated CAP would be treated with third generation cephalosporins. However, almost $80 \%$ of cases over the entire study period were treated with penicillins. Third generation cephalosporins were used in only $13 \%$ of cases and varied by less than one percent pre- and post-CDSS. There was an apparent tendency toward the use of combination therapy in the post-CDSS period, although the difference in pre-CDSS versus post-CDSS usage was not statistically significant. Restricted antibiotics were infrequently used in both periods. Where restricted cephalosporins, azithromycin, or lincosamides were used, they were never accompanied by CDSS approval, suggesting the CDSS was not used when this antibiotic decision-making took place.

Published evaluations report varying CDSS utilisation rates and impact on prescribing. ${ }^{12}$ Access to training, adequacy of computer skills, and a belief that a CDSS improves prescribing are considered facilitators to utilisation. These are reinforced by organisational support including senior staff endorsement. In contrast, poorly integrated systems - perceived to detract from patient-doctor interactions or create a divergence from usual workflow - are often considered barriers. ${ }^{12}$

Prescribing for CAP is usually initiated in the ED where antibiotic prescribing is predominantly monitored by pharmacists. ${ }^{13}$ Unobstructed access to restricted antibiotics in our hospital's ED and general medical wards, together with a lack of pharmacist monitoring (i.e. absence of ED pharmacist rounds, limited pharmacist rounds on general medical wards) might have further contributed to the apparent lack of impact of the CDSS on prescribing for CAP. Without regular pharmacist monitoring and poor integration with the prescriber's usual workflow, there were no prompts to use the CDSS at any point from antibiotic decision-making to the moment of administration. Thus, any theoretical improvement in prescribing or CDSS utilisation would have relied on general prescriber knowledge of AMS policy and routine AMS activity. As most assessed cases of CAP pre-CDSS were treated according to printed guidelines without the need for specific approval prescribers and nursing staff may have considered CDSS to be of minimal benefit. ${ }^{12}$ 
Antibiotic decision-making in ED occurs in the context of a busy working environment. There are constant interruptions, ${ }^{14}$ limited diagnostic information, ${ }^{15}$ and pressure to minimise patient waiting times. ${ }^{16}$ Due to these constraints, the preferred strategies for AMS in ED are efficient, workflowintegrated systems with a degree of flexibility. ${ }^{15}$ However, integration does not guarantee uptake, ${ }^{17}$ and even efficient, integrated interventions have been poorly utilised in some EDs. ${ }^{17}$ Locally, our CDSS platform has resulted in statistically significant reductions in the overall use of broad-spectrum antibiotics in adult hospitals. ${ }^{18}$ However, third generation cephalosporins were still overused for moderate CAP in some hospitals, with rates only reduced after more intensive audit, feedback and education was introduced. ${ }^{19}$ Similar assessments of CDSS impact on overall antimicrobial consumption in our hospital has been limited by a lack of feasible and widely accepted measures to monitor use in paediatrics. ${ }^{20}$ Unlike adult hospitals without electronic prescribing or administration records there is no paediatric equivalent for the world health organization's defined daily dose for adults. ${ }^{21}$ As a result, the CDSS is often used by the local AMS to monitor antimicrobial use.

CAP guidelines for children when supported by a range of AMS strategies have been reported to result in significant improvements in the rate of penicillin use. Guideline concordant prescribing increased from median baseline of $0 \%$ to $100 \%$ in $\mathrm{ED}$ and $30 \%$ to $100 \%$ among resident medical teams within 6 months by applying targeted quality improvement methodology with weekly reports on prescribing. ${ }^{22}$ Elsewhere, prescribing improved but rates of broad-spectrum use remained higher than those observed in our study. ${ }^{4}$ At our site, it may be that introducing a CDSS was insufficient to increase already comparatively guideline-concordant prescribing for CAP, without specific targeted intervention directed at CAP prescribing.

This study has several potential limitations. Our cohort of cases was identified using ICD-10-AM codes and the ED or admitting medical team's documented clinical impression. Coding relies on good clinical documentation and is therefore prone to insensitivity and non-specificity. ${ }^{23}$ Acknowledging the potential influence of coding, we chose to include a broad range of ICD-10-AM codes associated with pneumonia and confirmed these as relevant cases only after review of medical records and agreement between the two independent reviewers. Patients under 3 months of age may have been inadvertently excluded by coding or the clinician's initial risk assessment. We did not collect detailed age data in excluded patients and were therefore unable to confirm the underlying cause. We did not 
assess prior antibiotic use, either as a factor in antibiotic decision-making or as part of our exclusion criteria, although this may have influenced the prescriber's decisions. As we were unable to obtain adequate numbers of records and observed unexpectedly high rates of appropriate prescribing preCDSS our study was not sufficiently powered to exclude small improvements in prescribing. Finally, we were not able to consistently determine the oxygen saturation at the time of admission and exclude severe cases based on oxygen requirements which may have been an important consideration. ${ }^{11}$

Despite these limitations, the study has provided insights to inform targeted AMS activities that aim to maximise CDSS utilisation. Nurse-focussed strategies include rationalising the range and number of restricted agents stored in ward areas, integration of the traffic light system into ward medication rooms and resources used by nurses when preparing antibiotics. Since February 2017, utilisation among JMO's has been encouraged through regular peer audits of compliance reported as departmental scorecards. In addition, the transition from paper-based to electronic medical records in combination with a more streamlined CDSS approval process via the electronic medical record has provided a platform to promote CDSS utilisation in ED.

Further studies are required to monitor CDSS utilisation and evaluate impact on a broader set of indications and aspects of good antibiotic use such as timely switch from intravenous to oral therapy and optimal treatment duration.

Conclusion

CDSS implementation and need for approval was not associated with a further reduction in already low rates of third generation cephalosporin use for children with presumed uncomplicated CAP. 


\section{References}

1. McCulloh RJ, Patel K. Recent Developments in Pediatric Community-Acquired Pneumonia. Curr Infect Dis Rep. 2016;18(5):1-7. doi:10.1007/s11908-016-0521-1.

2. Bradley JS, Byington CL, Shah SS, et al. The management of community-acquired pneumonia in infants and children older than 3 months of age: Clinical practice guidelines by the pediatric infectious diseases society and the infectious diseases society of America. Clin Infect Dis. 2011;53(7):1-52. doi:10.1093/cid/cir531.

3. Williams DJ, Hall M, Shah SS, et al. Narrow Vs Broad-spectrum Antimicrobial Therapy for Children Hospitalized With Pneumonia. Pediatrics. 2013;132(5):e1141-e1148.

4. Ross RK, Hersh AL, Kronman MP, et al. Impact of Infectious Diseases Society of America/Pediatric Infectious Diseases Society Guidelines on Treatment of CommunityAcquired Pneumonia in Hospitalized Children. Clin Infect Dis. 2014;58(6):834-838. doi:10.1093/cid/ciu013.

5. MacDougall C, Polk RE. Antimicrobial Stewardship Programs in Health Care Systems. Clin Microbiol Rev. 2005;18(4):638-656. doi:10.1128/cmr.18.4.638-656.2005.

6. Gerber Matthew P; Ross, Rachael K; Hersh, Adam L; Newland, Jason G; Metjian, Talene A; Zaoutis, Theoklis E JSK. Identifying Targets for Antimicrobial Stewardship in Children's Hospitals. Infect Control Hosp Epidemiol. 2013;34(12). 
7. Clinical Excellence Commission. Paediatric Quality Program: Between the flags. http://www.cec.health.nsw.gov.au/patient-safety-programs/paediatric-patient-safety/pqpbetween-the-flags. Accessed August 16, 2017.

8. Newman RE, Hedican EB, Herigon JC, Williams DD, Williams AR, Newland JG. Impact of a Guideline on Management of Children Hospitalized With Community-Acquired Pneumonia. Pediatrics. 2012;129(3):e597-e604. doi:10.1542/peds.2011-1533.

9. Faul F, Erdfelder E, Lang A-G, Buchner A. G*Power 3: A flexible statistical power analysis program for the social, behavioral, and biomedical sciences. Behav Res Methods. 2007;39(2):175-191.

10. Usonis V, Ivaskevicius R, Diez-domingo J, et al. Comparison between diagnosis and treatment of community-acquired pneumonia in children in various medical centres across Europe with the United States , United Kingdom and the World Health Organization guidelines. Pneumonia. 2016:1-10. doi:10.1186/s41479-016-0005-y.

11. Shah SN, Bachur RG, Simel DL, Neuman MI. Does This Child Have Pneumonia? The Rational Clinical Examination Systematic Review. JAMA. 2017;318(5):462-471. doi:10.1001/jama.2017.9039.

12. Moxey A, Robertson J, Newby D, Hains I, Williamson M, Pearson S-A. Computerized clinical decision support for prescribing: provision does not guarantee uptake. $J$ Am Med Informatics Assoc. 2010;17(1):25-33. doi:10.1197/jamia.M3170.

13. Welch S. Antimicrobial stewardship in Australian emergency departments. EMA - Emerg Med Australas. 2015;27(5):427-430. doi:10.1111/1742-6723.12448.

14. Coiera EW, Jayasuriya RA, Hardy J, Bannan A, Thorpe MEC. Communication loads on clinical staff in the emergency department. Med J Aust. 2002;176(May):415-418.

15. Chung P, Scandlyn J, Dayan PS, Mistry RD. Working at the intersection of context, culture, and technology: Provider perspectives on antimicrobial stewardship in the emergency department using electronic health record clinical decision support. Am J Infect Control. 2017;45(11):1198-1202. doi:10.1016/j.ajic.2017.06.005.

16. NSW Health. Emergency Department Care. Health System Purchasing and Performance. http://www.health.nsw.gov.au/Performance/Pages/emergency.aspx. Accessed September 5, 2017.

17. Demonchy E, Dufour J-C, Gaudart J, et al. Impact of a computerized decision support system on compliance with guidelines on antibiotics prescribed for urinary tract infections in 
emergency departments: a multicentre prospective before-and-after controlled interventional study. J Antimicrob Chemother. 2014;69(10):2857-2863. doi:10.1093/jac/dku191.

18. Bond S, Chubaty AJ, Adhikari S, et al. Outcomes of multisite antimicrobial stewardship programme implementation with a shared clinical decision support system. $J$ Antimicrob Chemother. 2017;72(7):1-9. doi:10.1093/jac/dkx080.

19. Bond SE, Boutlis CS, Yeo WW, Miyakis S. Impact of an antimicrobial stewardship intervention on appropriateness of prescribing for community-acquired pneumonia in an Australian regional hospital. Intern Med J. 2017;47(5):582-585. doi:10.1111/imj.13401.

20. Fortin É, Fontela PS, Manges AR, Platt RW, Buckeridge DL, Quach C. Measuring antimicrobial use in hospitalized patients: a systematic review of available measures applicable to paediatrics. J Antimicrob Chemother. 2014. doi:10.1093/jac/dku003.

21. Irwin A, Sharland M. Measuring antibiotic prescribing in hospitalised children in resourcepoor countries: A systematic review. J Paediatr Child Health. 2013;49(3):185-192. doi:10.1111/j.1440-1754.2011.02126.x.

22. Ambroggio L, Thomson J, Kurowski EM, et al. Quality improvement methods increase appropriate antibiotic prescribing for childhood pneumonia. Pediatrics. 2013;131(5):e1623e1631.

23. Drees M, Gerber JS, Morgan DJ, Lee GM. Research Methods in Healthcare Epidemiology and Antimicrobial Stewardship: use of Administrative and Surveillance Databases. Infect Control Hosp Epidemiol. 2016;11(37):1278-1287. 
Figure 1. Local empiric antibiotic guidelines for paediatric community acquired pneumonia^

\begin{tabular}{|c|c|c|}
\hline CONDITION & AGE & ANTIBIOTIC (MAXIMUM DOSE) \\
\hline Pneumonia & $<3 m$ & $\begin{array}{l}\text { benzylpenicillin } 60 \mathrm{mg} / \mathrm{kg} 6 \text { hourly } \\
\& \text { gentamicin** } \\
\text { ADD azithromycin } 10 \mathrm{mg} / \mathrm{kg} \text { daily if pertussis OR chlamydia suspected }\end{array}$ \\
\hline $\begin{array}{l}\text { Severe } \\
\text { Pneumonia }\end{array}$ & $<3 \mathrm{~m}$ & $\begin{array}{l}\text { cefotaxime } 50 \mathrm{mg} / \mathrm{kg} 6 \text { hourly } \\
\& \text { clindamycin } \pm \\
\& \text { azithromycin } 10 \mathrm{mg} / \mathrm{kg} \text { daily } \\
\text { ADD vancomycint† if Shocked OR ICU } \\
\text { ADD aciclovir if at risk of HSV Pneumonitis }\end{array}$ \\
\hline $\begin{array}{l}\text { Mild } \\
\text { pneumonia }\end{array}$ & $\geq 3 m$ & $\begin{array}{l}\text { ORAL amoxycillin } 25 \mathrm{mg} / \mathrm{kg}(500 \mathrm{mg}) 8 \text { hourly } \\
\text { OR roxithromycin } 4 \mathrm{mg} / \mathrm{kg}(150 \mathrm{mg}) 12 \text { hourly if considering mycoplasma }\end{array}$ \\
\hline $\begin{array}{l}\text { Moderate } \\
\text { pneumonia }\end{array}$ & $\geq 3 \mathrm{~m}$ & $\begin{array}{l}\text { benzylpenicillin } 30 \text { to } 60 \mathrm{mg} / \mathrm{kg}(2.4 \mathrm{~g}) 6 \text { hourly } \\
\text { \& ORAL roxithromycin } 4 \mathrm{mg} / \mathrm{kg}(150 \mathrm{mg}) 12 \text { hourly if risk of mycoplasma }\end{array}$ \\
\hline $\begin{array}{l}\text { Severe/ } \\
\text { Complicated } \\
\text { pneumonia } \\
\text { Consult } \\
\text { respiratory }\end{array}$ & $\geq 3 m$ & $\begin{array}{l}\text { lincomycin } 15 \mathrm{mg} / \mathrm{kg} 8 \text { hourly }(600 \mathrm{mg} \text { ) } \\
\& \text { cefotaxime } 25 \text { to } 50 \mathrm{mg} / \mathrm{kg}(2 \mathrm{~g}) 8 \text { hourly (OR ceftriaxone } 50 \mathrm{mg} / \mathrm{kg}(2 \mathrm{~g}) \text { daily) } \\
\text { ADD vancomycint† if severe sepsis or requiring ventilatory support } \\
\text { ADD azithromycin if considering atypicals }\end{array}$ \\
\hline \multicolumn{3}{|c|}{$\begin{array}{l}\text { UNLESS OTHERWISE STATED MEDICATIONS ARE TO BE GIVEN INTRAVENOUSLY } \\
{ }^{*} \text { See Once Daily Gentamicin Guideline for dosing and monitoring recommendations } \\
\text { †† See Vancomycin Guideline for dosing and monitoring recommendations } \\
\pm \text { Clindamycin dosing varies with age-see recommendations in Guidance MS }\end{array}$} \\
\hline
\end{tabular}

Abbreviations: $3 \mathrm{~m}$ : 3 months of age

$\wedge^{\wedge}$ Lanyard card supplied to local hospital staff 
Figure 2. Criteria for mandatory clinical review by a medical officer within 5 minutes ${ }^{\#}$

Tachypnoea (respiratory rate in breaths per minute): $3-12$ months $>65 ; 1-4$ years $>60 ; 5-11$ years $>50 ; 12$ years and older $>40$

Tachycardia (heart rate in beats per minute) $3-12$ months $>180 ; 1-4$ years $>170 ; 5-11$ years $>160 ; 12$ years and older $>150$

Respiratory Distress (any of): new onset stridor, imminent airway obstruction, drowsy, unable to cry, feed or suck, exhaustion, gasping, grunting, extreme pallor, cyanosis, absent breath sounds, apnoeic episodes, hypoxaemia not corrected with oxygen

Altered consciousness (Alert Voice Pain Unresponsive scale): rousable on central pain or unresponsive, or equivalent paediatric Glasgow Coma Scale

\# Criteria used across all New South Wales hospitals (7) 
Figure 3. Process and criteria applied to identify cases of uncomplicated community acquired pneumonia in children before and after implementation of clinical decision support and approval system for restricted antimicrobials

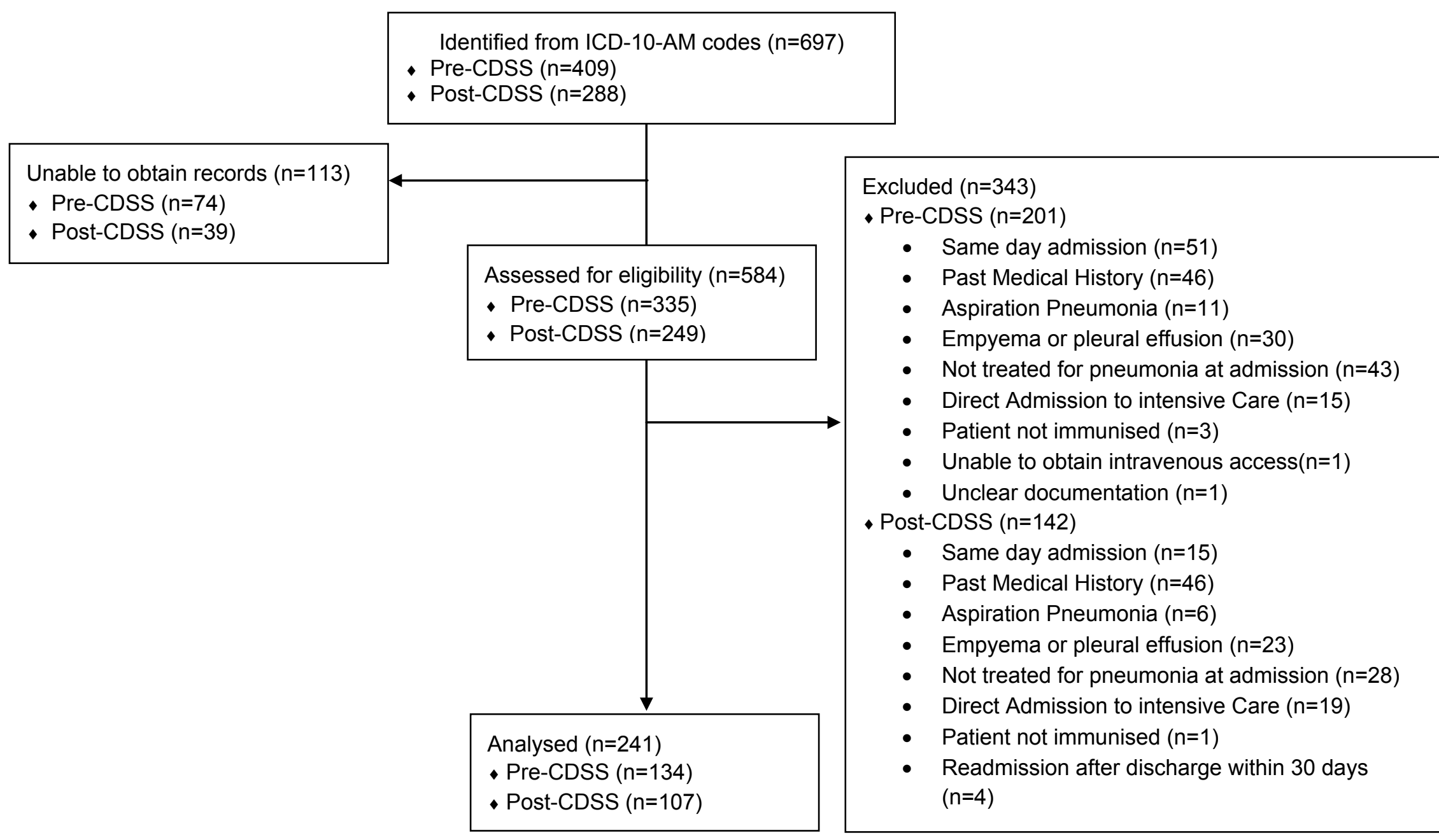

This article is protected by copyright. All rights reserved. 
Abbreviations: CDSS: Computerised clinical decision support and approval system; ICD-10-AM: The International Statistical Classification of Diseases and Related Health Problems Australian Modification 10th revision 
Table 1. Demographics and clinical status of study patients prior to antibiotic decision making ${ }^{*}$

\begin{tabular}{|c|c|c|c|}
\hline Characteristics & $\begin{array}{c}\text { Pre-CDSS } \\
\text { n (\%) }\end{array}$ & $\begin{array}{c}\text { Post-CDSS } \\
\text { n (\%) }\end{array}$ & $\begin{array}{c}\text { Overall } \\
\text { n (\%) }\end{array}$ \\
\hline Cases of uncomplicated community acquired pneumonia & 134 & 107 & 241 \\
\hline \multicolumn{4}{|l|}{ Age at admission } \\
\hline $3-12$ months of age & $14(10.4)$ & $19(8.4)$ & $23(9.5)$ \\
\hline $1-4$ years & $83(61.9)$ & $68(63.6)$ & $151(62.7)$ \\
\hline 5-11 years & $33(24.6)$ & $28(26.2)$ & $61(25.3)$ \\
\hline 12 years or older & $4(2.9)$ & $2(1.9)$ & $6(2.5)$ \\
\hline Female & $68(50.8)$ & $49(45.8)$ & $117(48.6)$ \\
\hline \multicolumn{4}{|l|}{ Prescriber's documented indication at admission } \\
\hline Bacterial Pneumonia & $2(1.5)$ & 0 & $2(0.8)$ \\
\hline Atypical or Mycoplasma & $13(9.7)$ & $9(8.4)$ & $22(9.1)$ \\
\hline Lower Respiratory Tract Infection Unspecified & $105(78.4)$ & $90(84.1)$ & $195(80.9)$ \\
\hline Viral Pneumonia & $14(10.5)$ & $8(7.5)$ & $22(9.1)$ \\
\hline \multicolumn{4}{|l|}{ Primary Diagnosis Code } \\
\hline Viral Diagnosis Codes & $25(18.7)$ & $22(20.6)$ & $47(19.5)$ \\
\hline Bacterial Diagnosis Codes ${ }^{\wedge}$ & $19(14.2)$ & $19(17.8)$ & $38(15.8)$ \\
\hline Unspecified Diagnosis Codes $^{\wedge \wedge}$ & $90(67.2)$ & $66(61.7)$ & $156(64.7)$ \\
\hline \multicolumn{4}{|l|}{ Signs of Severity } \\
\hline Tachypnoea (respiratory rate in "red zone")" & $18(13.4)$ & $18(16.8)$ & $36(14.9)$ \\
\hline Sign of severe respiratory distress ${ }^{\#}$ & $4(3.0)$ & $4(3.7)$ & $8(3.3)$ \\
\hline Supplemental oxygen administered $^{* *}$ & $41(30.6)^{* *}$ & $58(54.2)^{* *}$ & $99(41.1)$ \\
\hline Tachycardia $^{\#}$ & $18(13.4)$ & $19(17.8)$ & $37(15.4)$ \\
\hline Febrile (temperature $>38.5$ degrees Celsius) & $77(57.5)$ & $49(45.8)$ & $126(52.3)$ \\
\hline Altered Consciousness\# & $0(\mathrm{n} / \mathrm{a})$ & 0 (n/a) & 0 (n/a) \\
\hline \multicolumn{4}{|l|}{ Hospitalisation } \\
\hline Duration of inpatient stay in days, median (IQR) & $2(1-3)$ & $2(1-3)$ & $2(1-3)$ \\
\hline Readmission to any hospital within 28 days & $6(4.5)$ & $3(2.8)$ & $9(3.7)$ \\
\hline
\end{tabular}

Abbreviations: CDSS: Computerised clinical decision support and approval system; ICD-10-AM: The International Statistical Classification of Diseases and Related Health Problems Australian Modification 10th revision; IQR: Interquartile range; *time of documented decision to treat with antibiotics where there was no recorded time on the prescriber's medical note the time of antibiotic administration was used; ^Viral diagnosis codes (J10.0, J11.0, J12.0, J12.1, J12.2, J12.8, J12.9); ^^ Bacterial Diagnosis Codes (J13, J15.2, J15.9, J15.7); ^^^Unspecified Diagnosis Codes (J18.0, J18.8, 
J18.9); \#Any vital sign observation recorded on age appropriate standard paediatric observation chart prior to antibiotic decision making that required immediate clinical review by a medical officer as part of system to minimise clinical deterioration across all New South Wales public hospitals.

Corresponding criteria are specified in Figure 1; ${ }^{* *} \mathrm{p}<0.001$, no other statistically significant differences observed. 
Table 2. Initial antibiotic therapy selected for children hospitalised with uncomplicated community acquired pneumonia ${ }^{*}$

\begin{tabular}{|c|c|c|c|}
\hline Antibiotics & $\begin{array}{l}\text { Pre-CDSS } \\
\mathrm{n}=134(\%)\end{array}$ & $\begin{array}{l}\text { Post-CDSS } \\
\mathrm{n}=107(\%)\end{array}$ & $\begin{array}{c}\text { Total } \\
\mathrm{n}=\mathbf{2 4 1}(\%)\end{array}$ \\
\hline Third generation cephalosporin & $17(12.7)$ & $14(13.1)$ & $31(12.9)$ \\
\hline Narrow-spectrum penicillin ${ }^{\wedge}$ & $109(81.3)$ & $83(77.6)$ & $192(79.7)$ \\
\hline Macrolide & $72(53.7)$ & $66(61.7)$ & $138(57.26)$ \\
\hline Azithromycin & $2(1.5)$ & $3(2.8)$ & $5(2.1)$ \\
\hline Erythromycin & $2(1.5)$ & $2(1.9)$ & $4(1.7)$ \\
\hline Roxithromyin & $68(50.8)$ & $61(57.0)$ & $129(53.5)$ \\
\hline Lincosamide & $0(\mathrm{n} / \mathrm{a})$ & $2(1.9)$ & $2(0.8)$ \\
\hline \multicolumn{4}{|l|}{ Empiric antibiotic regimen selected at admission } \\
\hline Single agent therapy & $70(52.2)$ & $49(45.8)$ & $119(49.4)$ \\
\hline Macrolide alone & $9(6.7)$ & $10(9.4)$ & $19(7.9)$ \\
\hline Narrow Spectrum penicillin alone & $54(40.3)$ & $33(30.8)$ & $87(36.1)$ \\
\hline Third generation cephalosporin alone & $7(5.2)$ & $6(5.6)$ & $13(5.4)$ \\
\hline Dual agent therapy & $64(47.8)$ & $58(54.2)$ & $122(50.6)$ \\
\hline $\begin{array}{l}\text { Combination third generation cephalosporin and } \\
\text { narrow spectrum penicillin }\end{array}$ & $1(0.8)$ & 0 (n/a) & $1(0.4)$ \\
\hline $\begin{array}{l}\text { Combination third generation cephalosporin and } \\
\text { macrolide }\end{array}$ & $9(6.7)$ & $6(5.6)$ & $15(6.2)$ \\
\hline $\begin{array}{l}\text { Combination third generation cephalosporin and } \\
\text { lincosamide }\end{array}$ & 0 (n/a) & $2(1.9)$ & $2(0.8)$ \\
\hline $\begin{array}{l}\text { Combination narrow spectrum penicillin and } \\
\text { macrolide }\end{array}$ & $54(40.3)$ & $50(46.7)$ & $104(43.2)$ \\
\hline
\end{tabular}

Abbreviations: CDSS: Computerised clinical decision support and approval system; *No statistically significant differences between pre- and post-CDSS; \# percentages based on total within pre-CDSS and post-CDSS groups; $\wedge^{\wedge}$ Cefotaxime or ceftriaxone; ${ }^{\wedge} \wedge$ Ampicillin, amoxycillin or benzylpenicillin 
Title: Impact of clinical decision support on empiric antibiotic prescribing for children with community acquired pneumonia

Manuscript Type: Original Article

Authors: Mona Mostaghim (1,2), Tom Snelling (3,4,5), Brendan McMullan (6,7), Yean Hsiang Ewe (8), Beata Bajorek (1)

\section{Affiliations:}

1. Graduate School of Health, University of Technology Sydney, NSW, Australia

2. Pharmacy Department, Sydney Children's Hospital, NSW, Australia

3. Department of Infectious Diseases, Princess Margaret Hospital for Children, Western Australia, Australia

4. Wesfarmers Centre of Vaccines \& Infectious Diseases, Telethon Kids Institute, University of Western Australia, Western Australia, Australia

5. Menzies School of Health Research, Charles Darwin University, Northern Territory, Australia

6. Department of Immunology and Infectious Diseases, Sydney Children's Hospital, New South Wales, Australia

7. School of Women's and Children's Health, University of New South Wales, New South Wales, Australia

8. Junior Medical Unit, Sydney Children's Hospital, New South Wales, Australia

\section{Corresponding Author:}

Mona Mostaghim,

C/O Pharmacy

Sydney Children's Hospital,

High St, Randwick,

NSW, Australia, 2031

Telephone: +61293824781

Fax: +61293821369

Email: Mona.Mostaghim@health.nsw.gov.au

This article is protected by copyright. All rights reserved. 


\section{University Library}

\section{- M M N E R VA A gateway to Melbourne's research publications}

Minerva Access is the Institutional Repository of The University of Melbourne

Author/s:

Mostaghim, M;Snelling, T;McMullan, B;Ewe, YH;Bajorek, B

Title:

Impact of clinical decision support on empirical antibiotic prescribing for children with community-acquired pneumonia

Date:

2019-03-01

Citation:

Mostaghim, M., Snelling, T., McMullan, B., Ewe, Y. H. \& Bajorek, B. (2019). Impact of clinical decision support on empirical antibiotic prescribing for children with community-acquired pneumonia. JOURNAL OF PAEDIATRICS AND CHILD HEALTH, 55 (3), pp.305-311. https:// doi.org/10.1111/jpc.14191.

Persistent Link:

http://hdl.handle.net/11343/285131 